\title{
Frontier Research in Astrophysics - III Concluding Address
}

\author{
Franco Giovannelli*广 \\ INAF - Istituto di Astrofisica e Planetologia Spaziali, Via del Fosso del Cavaliere, 100, 00133 \\ Roma, Italy \\ E-mail: Eranco.qiovannellidiaps.inaf.it
}

Before officially concluding this workshop (and it is far beyond my powers to attempt some concluding remarks beyond those already dealt with on the various burning questions presented by Gennady Bisnovatyi-Kogan, Paul Mason, Janusz Ziółkowski, and René Hudec), I would like to comment on a few highlights coming from our fruitful week of discussions about Frontier Research in Astrophysics - III, without any pretension of completeness.

Frontier Research in Astrophysics - III (FRAPWS2018)

28 May - 2 June 2018

Mondello (Palermo), Italy

* Speaker.

${ }^{\dagger}$ A footnote may follow. 


\section{My Personal Comments}

We know for sure that "The Bridge between the Big Bang and Biology" undoubtedly exists, as discussed in the book edited by Giovannelli (2001). The big problem is how to cross this bridge, and the main question is: what are the experimental tools for understanding the pillars of this Bridge?

During this workshop we have discussed about those experimental tools that have provided a huge amount of data useful for improving our knowledge of the physics governing our Universe. These data are coming from big and small experiments ground- and space-based.

From the many talks presented it appears, although often masked, a continuity between the infinitely small to infinitely big. And in this line we have discussed problems of:

- Cosmology: Cosmic Background, Dark Matter, Dark Energy, Clusters of Galaxies, Gravitational Waves.

- Physics of the Diffuse Cosmic Sources.

- Physics of Cosmic Rays.

- Physics of Discrete Cosmic Sources.

- Extragalactic Sources: Active Galaxies, Normal Galaxies, Gamma-Ray Bursts.

- Galactic Sources: Star Formation, Pre-Main-Sequence and Main-Sequence Stars, Cataclysmic Variables and Novae, Supernovae and SNRs, X-Ray Binary Systems, Pulsars, Black Holes, Gamma-Ray Sources, Nucleosynthesis, Asteroseismology.

- Planetology: Solar System, Sun-like Stars, Exoplanets.

- Search for Life in Habitable Zone of the Galaxy.

- What "Intelligent" Humanity is doing.

- Science from large area multifrequency and multimessenger surveys and deep-exposure pointings.

- Future Physics and Astrophysics: Ongoing and Planned Ground- and Space-based Experiments.

It is important to remark that undoubtedly the advent of space-based observatories has given a strong impulse to astronomy. Starting roughly from the mid-seventies and over almost all of the electromagnetic spectrum, these observations have continuously surveyed the sky. Cataclysmic variables (CVs) historically were the first systems that demonstrated the need for studies of the accretion disk processes around white dwarfs (WDs). In fact, these studies began in the early 1960's with the schools of Warsaw (Poland) and Cambridge (UK). However, CVs rapidly lost their primeval importance because of the advent of the first X-ray space experiments that, with their limited sensitivity, were mostly detecting X-ray binary systems (XRBs). These showed abundant $\mathrm{X}$-ray emissions above the thresholds of their detectors. Of course, we now know that these sources 
emitted brightly thanks to the presence of neutron stars or black holes as companions of the optical low-mass or high-mass stars. The X-ray emission of CVs is about 2-3 orders of magnitude lower than that of XRBs. Thus the bulk of observations of CVs for a long time came from optical and UV regions, and sometimes from IR and occasionally from radio bands.

In the last decade, results coming from the new generation of satellites, especially in the hard $\mathrm{X}$-ray and $\gamma$-ray regions, renewed the interest of scientific community on CVs.

Indeed, among the cosmic systems where accretion processes occur, undoubtedly, non-magnetic $\mathrm{CVs}$, intermediate polars and polars constitute the most powerful probe to test our theories of the various modes of accretion. The reason is rather simple: CVs are enough close to us and their processes develop in time-scales relatively easy to be followed and enough energetic to be easily detected. The long term evolution of CV systems accreting at a prohibitive rate has become a hot topic both in terms of the fate of such systems (all sorts of supernovae) and the microphysics of Eddington and super Eddington mass accretion and mass loss flows. In particular we stress one of the hottest topics in present day astrophysics, namely the progenitors of SN-Ia. This problem is connected with fundamental issues in cosmology. Novae and recurrent novae are the most promising progenitor candidates but so far could not be nailed down.

\section{Some General Remarks}

This workshop again affirms the importance of Multifrequency Astrophysics. However, there are many problems in performing Simultaneous Multifrequency, Multisite, Multiinstrument, Multiplatform and Multienergy measurements due to: i) objective technological difficulties; ii) sharing common scientific objectives; iii) problems of scheduling and budgets; and iv) the politic management of science.

With the detection of gravitational waves (GW) from a merging of two neutron stars occurred on August 17, 2017 Multimessenger Astrophysics born! As pioneers of the Multifrequency Astrophysics, I am particularly happy!

I dare to remind two interesting great examples of synergy between Physics and History:

- Sedov's relation revisited. Bernd Aschenbach (2016) modified Sedov's relation for determining the age of supertnova remnants (SNRs).

As test, he used the SNR Vela Jr (RX 0852.0-3946), and he gave an age of $\sim 725 \mathrm{yr}$, contrary to $\mathrm{t}_{\text {Sedov }}=1714 \mathrm{yr}$.

Historical document (Tatsunokuchi Persecution of Nichiren Daishonin - the Buddha of the last day of the law) supports this result with an exceptional precision: The date of the explosion was 12 September 1271 ( $1 \pm 2$ a.m.) (between the hours of the rat and the ox) (Soka Gakkai International, 1999)

- The Nova Scorpii AD 1437 (Clark \& Stephenson, 1977). Joanna Mikolajewska (2017) reports that Chinese and Korean witnesses noted the appearance of strange light in the sky corresponding to the date of the apparition of the Nova Sco AD 1437, and its coordinates (Shara et al., 2017). 
And two clear examples of biased referee process:

- Gamma-Ray Burst Models: the Cannonball (CB) model - claimed as the best for fitting GRBs by Arnon Dar and collaborators since beginning of 1990 - was not accepted by the international community because the Fireball model (FB) was the most popular and accepted by the international community. However, recently, Dado \& Dar (2016) discussed on the critical test of gamma-ray bursts theories and demonstrated definitively the validity of the CB model against the popular FB model (Piran, 1999).

- In 1975 Giulio Auriemma, Enrico Costa, Franco Giovannelli, Gastone Medici, and Pietro Ubertini (at that time student) made a "Proposal for an Experiment with High Angular Resolution to Observe Extragalactic Sources in the Range 20-100 keV" by using our hard X-ray detectors position sensitive that we developed before for soft X-rays in order to search for hard X-ray emission from Clusters of Galaxies...

...The Italian expert theoreticians stopped the Proposal...23 years before the discovery of hard X-ray emission from Clusters of Galaxies made by BeppoSAX (Fusco-Femiano et al., 1999).

During this fruitful workshop, we hope to have demonstrated once more the "Vulcano Theorem" enunciated in 1984 in my concluding address of the first historical workshop on Multifrequency Behaviour of Galactic Accreting Sources: It is possible to develop science seriously even if smiling (Giovannelli, 1985).

But, as you probably suspected, this workshop has been organized under "Peaceful Surroundings". For this reason I want to conclude with a few wonderful words of Dr Daisaku Ikeda (2001a) president of the Soka Gakkai International (SGI) - reported in the booklet For Today and Tomorrow - the thought of 30th May:

"The one who has many friends has greater opportunities for growth. In this way, one both makes society a better place, and lives happier and more satisfied. In all cases, human relations, inter-personal interaction and communication are of vital importance. We must establish and nurture friendship and contacts with many people, both in our environment, and in society in general.

In this manner our life will open up and will flourish".

We could go back to early childhood when we were as the "Little Prince". To quote:

One sees clearly only with the heart. What is essential is invisible to the eye (from The Little Prince by Antoine de Saint Exupéry, 1943).

The search for the essential is of extreme interest to a large number of men of great learning. These are in agreement with Paul Salahuddin Armstrong, who said in his 2014 talk "Human Family; Past, Present and Future", at the "New Humanity Movement-Event" (Paul Salahuddin Armstrong, 2014):

Today we travel the world, making connections, doing business, and building relationships in person or online with fellow members of our Human Family from all parts of the Earth. We are becoming more conscious that what happens in one place affects people everywhere. We are not 
alone... We are not isolated... Only through building bridges of Love and Understanding can we insure the well-being of everyone in our Human Family.

The search for the essential is so important that even famous, noble-minded scientists try to attempt the difficult way of the possible convergence of science and life in its more sublime meaning. For instance, Pier Luigi Luisi founded in 1985 the International Week of Cortona "Science and the Wholeness of Life", dedicated to the integration of Scientific Disciplines and Humanities. Later he published the book, "The Emergence of Life. From Chemical Origins to Synthetic Biology (Luisi, 2006) in which he reviewed the consecutive stages from prebiotic chemistry to synthetic biology, uniquely combining both approaches. Indeed, the origin of life from inanimate matter has been the focus of much research for decades, both experimentally and philosophically. Friedrich Rolle, a German philosopher and biologist, wrote "The general reasons for this assumption are so categorical that I have no doubt that sooner or later it will be possible to demonstrate such an assumption in an unambiguous and scientific way, or even repeat the process experimentally (Rolle, 1863).

In the book "The Systems View of Life: A Unifying Vision" (Capra \& Luisi, 2014) those authors integrate in a single framework of coherent thought the ideas, models and theories that are the foundation of the systemic vision of life, highlighting its economic, ecological, political and spiritual implications.

Personally, I would like to reiterate and underscore some fundamental concepts in the book, which I completely share.

Life is a network of complex and inseparable relationships that renders the understanding of an individual phenomenon indivisible from the understanding the entire ecosystem in which it occurs. Therefore the answers can not be found by relying exclusively to the scientific method. A "holistic" approach is now required, one that is able to reflect on connectivity, relationships and contexts as well as properties and functions of the individual parts.

The discipline that best reflects the systemic vision of life is ecology, which reconnects the life sciences with the earth sciences and studies the interaction of organisms with each other and with the surrounding environment. The new ecological science - that has emerged from organismic biology only in the late twentieth century when the concept of ecosystem developed - is not anthropocentric but eco-centric. That is characterized by the awareness that all living things are tied together in networks of interdependence.

Ecology is the ideal bridge between science and spirituality. In fact, within the systemic view of life, it is essentially the concept of balance between science - responsible for material and technological progress - and spirituality, responsible for the internal growth of individuals and ethical limitations imposed by the excessive consumption of the resources of the planet. The balance between science and spirituality determines the welfare of society.

The Bridge between the Big Bang and Biology (e.g. Giovannelli, 2001) ferries us from the original point to the biologically active side where sentient life and, then science, start. But to close correctly the "run" of it, it is necessary to cross one bridge more: the bridge between science and spirituality. If this bridge is properly covered, our society will flourish.

Personally, I feel obligated to point out some observations that seem fundamental about the philosophical and social implications of contemporary science. These observations lead to interesting conclusions about the origin of life and the self-organization of natural and synthetic systems. These findings are in keeping with the Buddhist view of the Universe. It is understood as a living 
organism being composed of myriads of components all related and interacting with one another. Life can be seen as a system of interconnected autopoietic systems. The organism interacts with the environment in a "cognitive" way. At the same time, the organism "creates" its own environment and the environment allows the creation of the organism. But this is the concept of dependent origin. According to this concept, every phenomenon is the product of the interaction of every other phenomenon in the Universe.

The consequence of this view are of extraordinary importance, above all in ethics: it asserts that all living beings and their environment are inextricably linked, and that their essence is not absolute but "of relationship". It leads us to respect every individual being and its inherent rights. In other words, this view leads us to live and act without distinguishing our own happiness from that of others. Ultimately this view leads to the TOTAL RESPECT OF LIFE in the most general meaning.

\section{The reason for the Etruscan Wine Party}

My full name is Franco Giovannelli Seghieri (father name: Flavio Giovannelli; mother name: Teresita Seghieri).

My ancestors of both families arrived to SUVERETO (a small medieval village close to Populonia, one of the most important Etruscan towns, before Romans) between the beginning and the middle of 19th Century. Giovannelli: an agricultural labourer family whose member Francesco grandfather of my great-grandfather Francesco - arrived from Tuscan-Emilian Appennini Mountains for searching farm work. Seghieri: a blazoned family from Montecarlo di Lucca whose member Metello - my great-grandfather - arrived as town clerk.

Suvereto, considered one of the most beautiful villages in Italy, is located between the hills and the shining sea of the Etruscan Coast. Immersed in the green Val di Cornia, the village is a real treasure: its walls preserve treasures made up of characteristic medieval streets, stone houses, historic buildings and evocative churches. All around exterminated forests of chestnuts, oaks and, of course, corks, hence the name of the locality. Indeed, the toponym is attested for the first time in 973 and derives from the Latin suber, "cork", in Italian "sughero". Then the name of the village was Sughereto (foresta di sughero = cork forest) that was changed to Suvereto due to the local pronunciation of sughero as suvero. Therefore, Suvereto is the "cork forest".

Suvereto, the small medieval village, is the town of wine and olive oil. Figure 1 shows some important parts of the village and surroundings.

Suvereto became, thanks to Ildebrandino VIII of the Aldobrandeschi, the first free municipality of Tuscany, with the issue of the "Charta Libertatis" in 1201, October 14th, which granted freedom of trade and government to the inhabitants of the town. It is from this period the construction of the "Palazzo Comunale" (village hall) with the loggia of judges ("Loggia dei Giudici"), where disputes between citizens were resolved. Baroncello, the first mayor of Suvereto elected by the people for treating with Ildebrandino VIII Aldobrandeschi, Count Palatino, the "Charta Libertatis". This important historical event is celebrated each year on December 8th in occasion of the "Sagra di Suvereto" (Suvereto Festival) after the historical cortege.

Baroncello is interpreted by Franco Giovannelli as shown in Fig. 2 (left panel), and Fig. 2 (right panel) shows a part of the historical cortege. 


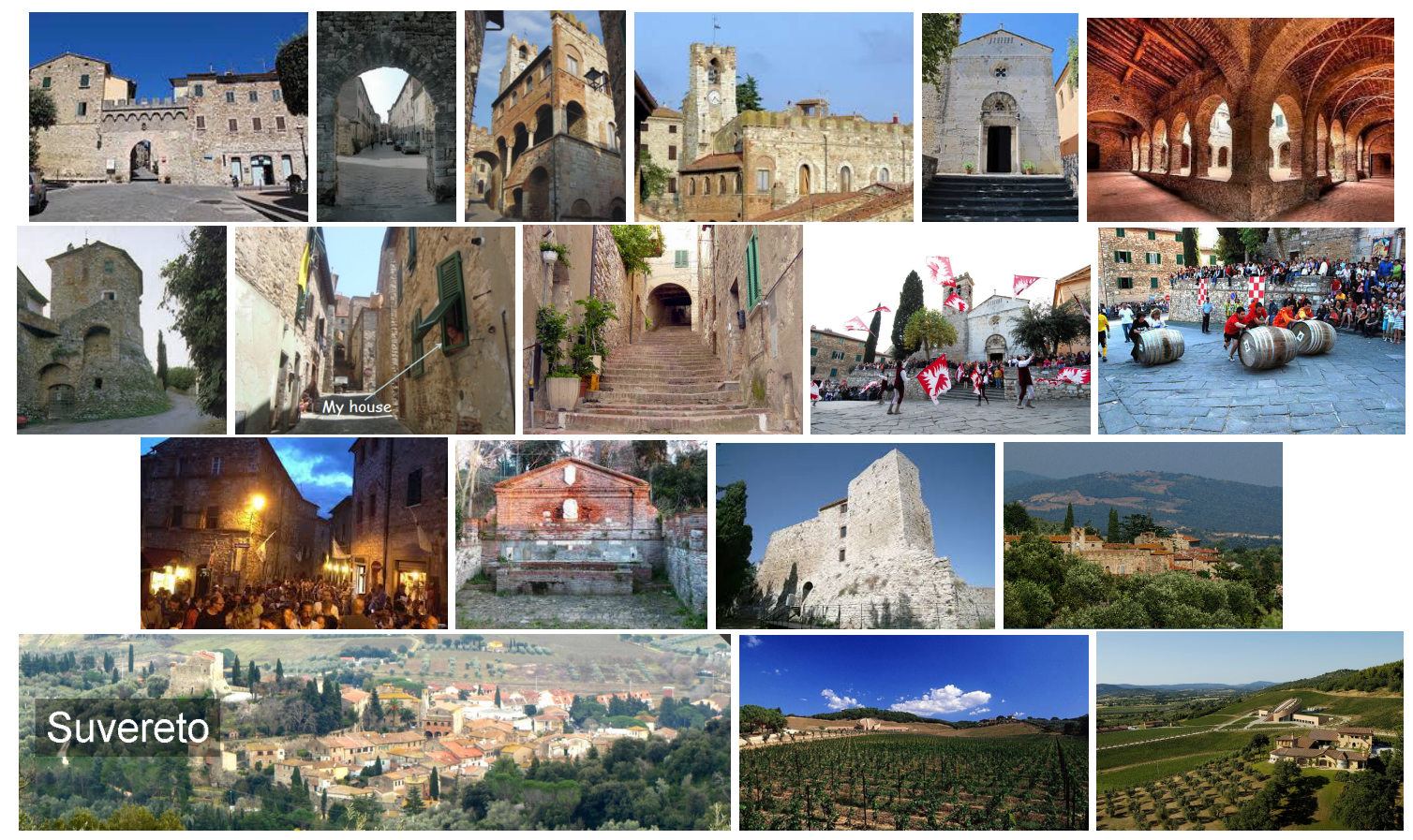

Figure 1: Suvereto. First line, from the left to right: The southern gate "La Porta" (1300 A.C.); The northern gate "La Porticciola" ( 1300 A.C.); The loggia of judges (XIII Century); The village hall (XIII Century); Romanesque church of San Giusto "Ecclesia S. Justi" (IX-XII Centuries); St. Francis cloister "Il Chiostro di San Francesco" (XII Century). Second line, from the left to right: The tower "Il Torrione" (XIV-XV Centuries); My House ( $\sim$ XV Century); Great staircase "Gli Scaloni" ( $\sim$ XIII-XVI Centuries); The flag bearers of the fifteenth century "Gli Sbandieratori"; The Palio of Santa Croce of the barrels. Third line, from the left to right: Goblets of stars "Calici di stelle" (10th August); The source of the angels "La Fonte degli Angeli" ( 1500); Fortress Aldobrandesca "Rocca Aldobrandesca" (XII Century); Partial panorama of Suvereto. Fourth line, from the left to right: General panorama of Suvereto; PETRA Vineyard in San Lorenzo (hamlet of Suvereto); PETRA Olive grove in San Lorenzo (hamlet of Suvereto). These two last photos show a part of the farm built by my great-grandfather Francesco and belonging to Giovannelli's family until 1961.

Despite having lived almost all my life in Rome, I have maintained a strong bond with Suvereto and with all my childhood friends. Until the harvest of 1960 I used to bring with a cart pulled by oxen the grapes to be fermented in a big vat, whose location was in "Casetta" - a typical farmhouse of the Maremma - belonging to the Casini and Petricci families. The Casini family moved to another place and the Petricci family instead continued to live there, where their vineyard thrives in the surrounding area. The young Petricci, who married a woman from the Del Pianta family, founded the Petricci-Del Pianta farm (Azienda Agricola Petricci-Del Pianta). From this company, which still uses the original vines of the area, come the wines consumed during the Etruscan Wine Party. Fig. 3 shows some pictures of the vineyard and wines produced by such a farm.

\section{The reason for the night performance}

The reason is very simple: every type of art increases knowledge and tones the soul. 

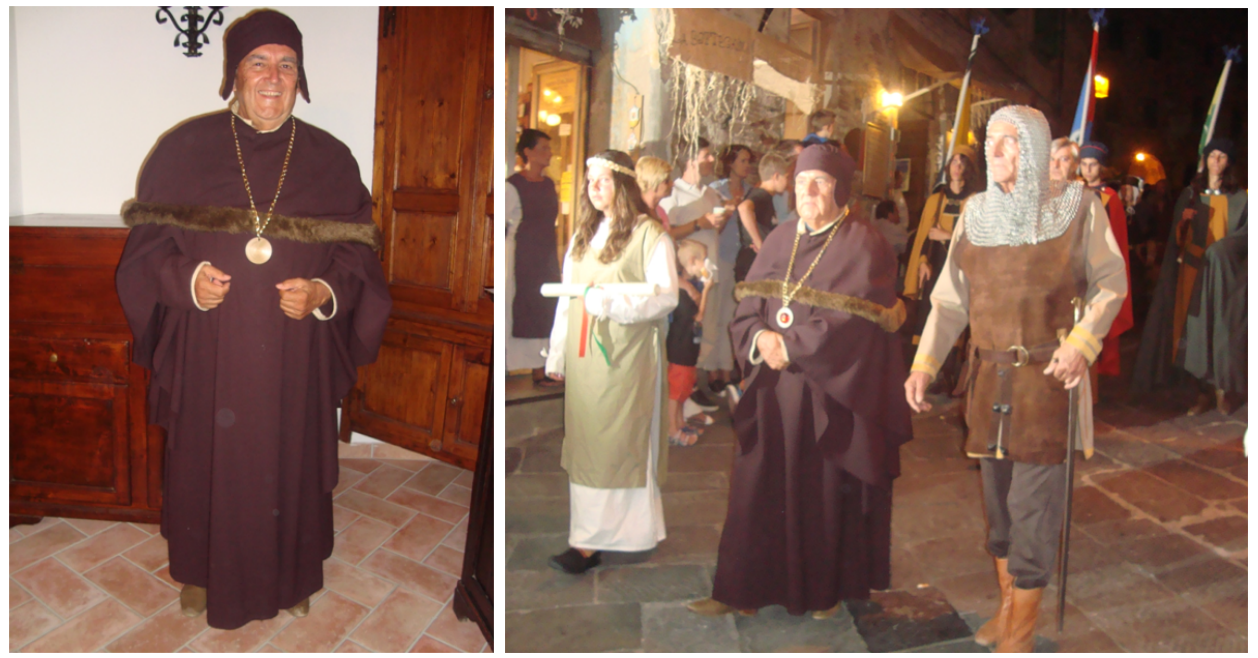

Figure 2: Left panel: Franco Giovannelli as Baroncello in his old house in Suvereto. Right panel: a part of the historical cortege celebrating the conquest of the "Charta Libertatis" in 1201.

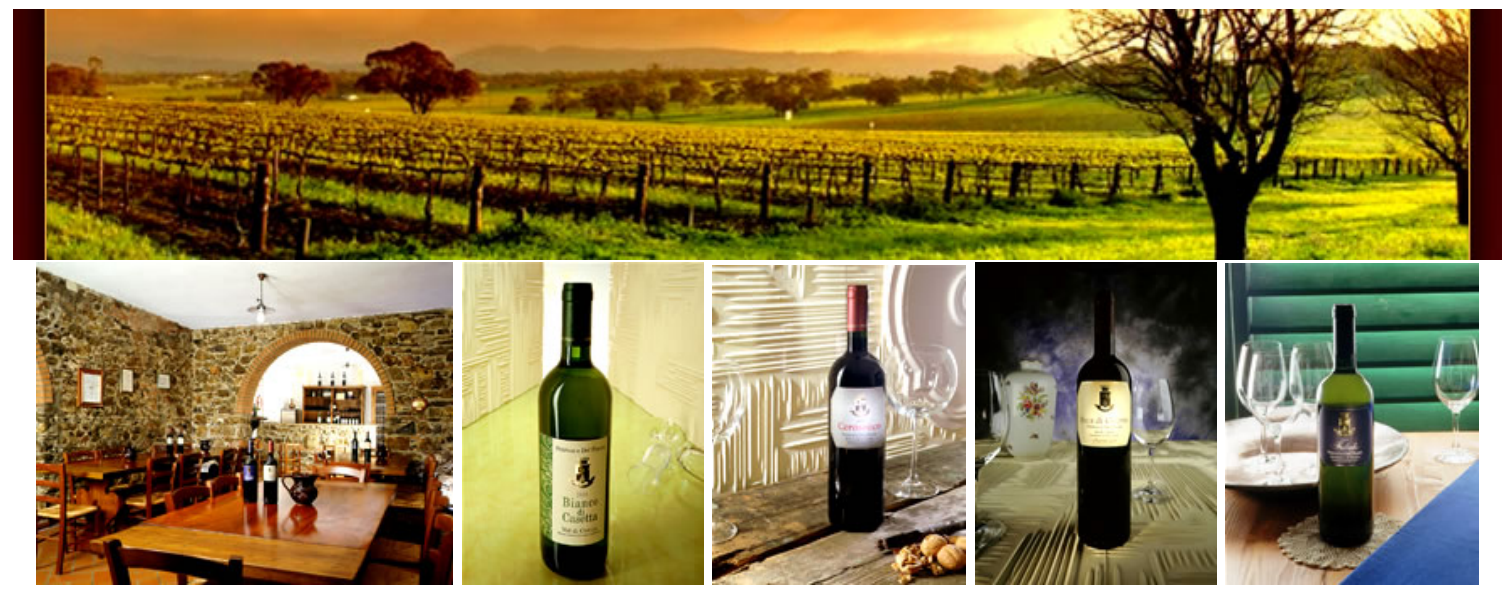

Figure 3: First line: a partial view of Petricci-Del Pianta vineyard. Second line from left to right: wine tasting cellar; Bianco di Casetta (white); Cerosecco (red); Buca di Cleonte (red); Fabula (white).

Physics is not just a science, but it is also a form of art, according to my judgment as I clearly pointed out in my concluding remarks of the "XIVth Cracow Summer School of Cosmology: The structure of space and time (Giovannelli, 1996).

\section{Conclusions}

In this workshop, the presence of women has been particularly pleasant and intentional as well as the presence of many young colleagues, some of them still $\mathrm{PhD}$ students.

This is the age of the youth. Young people do not depend on anyone or draw strength from others. The courage of young people is unparalleled. They fears nothing. The courage of youth is boundless, is the strength to never give up (Daisaku Ikeda, 2001b). 
Probably the most important scientist and artist ever born, Leonardo da Vinci, said Tristo è lo discepolo che non supera lo maestro suo!. Expressed in English, that reads as Grim is the disciple who does not exceed his master!

\section{Special thanks}

It is my pleasure to thank:

- the Scientific Organizing Committee (James Howarth Beall, Dmitry Bisikalo, Thomas Boller, Riccardo Claudi, Sergio Colafrancesco, Massimo Della Valle, René Hudec, Paolo Persi, Lola Sabau-Graziati, Andrea Santangelo, ... and myself).

- The super-efficient Local Organizing Committe (Daniela Giovannini, Bruno Luigi Martino, Rosa Poggiani, Francesco Reale,... and myself) shown in Fig. 4.

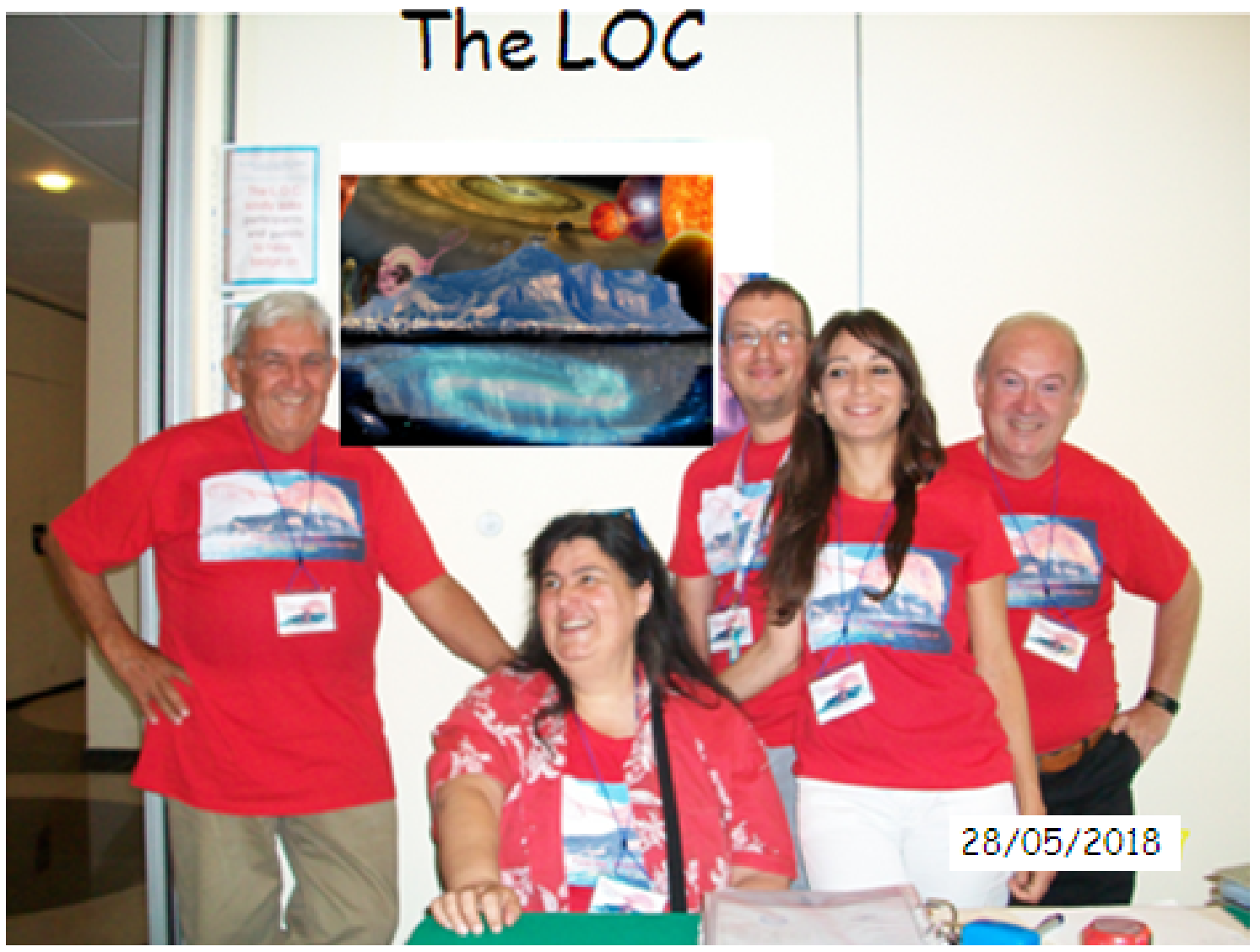

Figure 4: The extraordinary LOC. From the left to the right: Franco Giovannelli, Rosa Poggiani, Francesco Reale, Daniela Giovannini, Bruno Luigi Martino.

- Many thanks to the Directors of the: ASCR-AIO \& CTU, DCUCE-INTA, IAA, University Tübingen, INAF-IASF, INAF-OAC, INAF-OAP, MPE, NRL/SSD \& SJC RAS-AI, WITS University

The reasons for some absences at the workshop: 
- Lola Sabau-Graziati (SOC) could not come because of the urgent commitments in the INTA as Director of the "Cargas Utiles y Ciencias del Espacio" Department.

- Massimo Della Valle (SOC) did not come because of important obligation as Director of the INAF-Capodimonte Astronomical Observatory.

- Sergio Colafrancesco (SOC) could not come because of serious health problems we did not know. Indeed, unfortunately he passed away on Sunday, 30 September 2018, following a battle with cancer.

Particular warm thanks to:

- ALL SPEAKERS, who rendered this workshop very interesting and alive.

- ALL PARTICIPANTS, who breathed life into the workshop with their question-answers, and for the friendly atmosphere they provided.

- The FOUR COLLEAGUES and FRIENDS (Gennady, Paul, Janusz \& René) who kindly accepted the not so easy task of making the concluding remarks of the workshop.

- The actresses Flavia Giovannelli and Anna Lisa Amodio for their splendid Performance PO Box 1663 Santa Fe (The wives of Los Alamos).

- To all the staff of the SPLENDID Hotel La TORRE.

- Finally, on behalf of all participants, I would like to express my warm thanks to the Chèf, Mr Daniele Inzerillo, who prepared for us a large number of delicacies.

Many particular thanks to Francesco Reale: ISC/CNR (Alias FIGARO) for helping in informatics and solving all related problems during the preparation and development of the workshop and in Palermo, at the registration desk, in the conference room, on the terrace, and ... more, together with

- the Executive Secretary Daniela Giovannini: IFT/CNR who smoothed all the inconveniences that occurred at the registration desk with professionalism and moreover with her nice smile,

- Bruno Luigi Martino: IASI/CNR with his sincere kindness,

- Rosa Poggiani: Physics Dpt, Pisa University with a smiling face behind her professional camera.

Without the presence of Francesco it would not have been possible to organize the workshop!

Francesco, alias FIGARO, is shown in Fig. 5 during one of his usual runs for something urgent. He asked me to mention his commemoration for her good friend who passed away just when the workshop was in progress: "I want to dedicate my commitment to the preparation and carrying out of this workshop to my dear friend Giovanna Petitti. Dear Giovanna, thank you for everything you taught me!"

I hope to meet all of you once again during our next Mondello Workshop.

Acknowledgments This research has made use of NASA's Astrophysics Data System. 


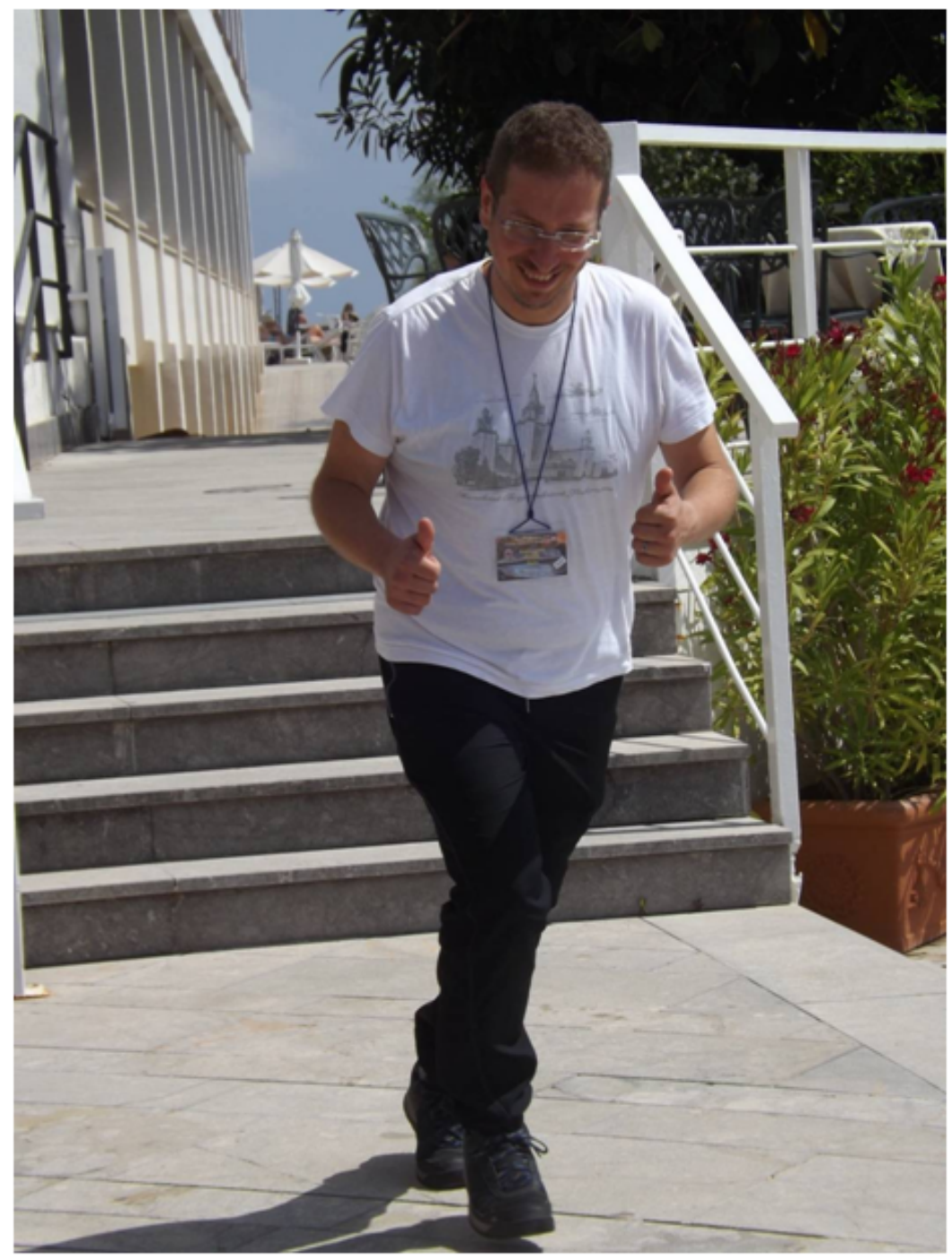

Figure 5: Francesco Reale, alias Figaro, running.

\section{References}

[1] Aschenbach, B.: 2016, in Frontier Research in Astrophysics II. Online at https://pos.sissa.it/cgi-bin/reader/conf.cgi?confid=269, id.36.

[2] Auriemma, G., Costa, E., Giovannelli, F., Medici, G., Ubertini, P.: 1975, Conferenza Italiana di Astronomia Extragalattica, Gruppo Nazionale di Astronomia (GNA) del CNR, Asiago. Internal Report del Laboratorio di Astrofisica Spaziale, CNR, No. 26 (1975).

[3] Buckley, D.A.H., Meintjes, P.J., Potter, S.B., Marsh, T.R., Gänsicke, B.T.: 2017, Nat. As. 1, id. 0029.

[4] Capra, F. \& Luisi, P.L.: 2014, The Systems View of Life: A Unifying Vision, Cambridge University Press.

[5] Clark, D.H., Stephenson, F.R.: 1977, The Galactic Supernovae, New York: Pergamon Press, 1st ed.

[6] Dado, S., Dar, A.: 2016, PhRvD 94, Issue 6, id.063007. 
[7] Fusco-Femiano, R., Dal Fiume, D., Feretti, L., Giovannini, G., Grandi, P. et al.: 1999, ApJ 513, Issue 1, L21-L24.

[8] Giovannelli, F.: 1985, in Multifrequency behaviour of galactic accreting sources, F. Giovannelli (Ed.), Edizioni Scientifiche SIDEREA, Roma, Italy, p. 371.

[9] Giovannelli, F.: 1996, in XIVth Cracow Summer School of Cosmology: The structure of space and time, Concluding Remarks, Institute of Physics, Łódź University, Poland, pp. 147-150.

[10] Giovannelli, F. (Ed.): 2001, The Bridge between the Big Bang and Biology (Stars, Planetary Systems, Atmospheres, Volcanoes: Their Link to Life), President Bureau of the CNR, Roma, Italy, pp. 1-440.

[11] Giovannelli, F., Sabau Graziati, L.: 2015, in The Golden Age of Cataclysmic Variables and Related Objects - III, online at http://pos.sissa.it/cgi-bin/reader/conf.cgi?confid=246, id.1.

[12] Ikeda, D.: 2001a, For Today and Tomorrow - The thought of 30th May, Edizioni Esperia, Italy.

[13] Ikeda, D.: 2001b, For Today and Tomorrow - The thought of 11th June, Edizioni Esperia, Italy

[14] Isern, J., Hernanz, M., García-Berro, E.: 1993, in White Dwarfs: Advances in Observation and Theory, M.A. Barstow (ed.), Kluwer Academic Publ., Dordrecht, Holland, NATO ASI Ser., C403, 139.

[15] Isern, J., Hernanz, M., Abia, C., José, J.: 1997, in Frontier Objects in Astrophysics and Particle Physics, F. Giovannelli \& G. Mannocchi (eds.), Italian Physical Society, Editrice Compositori, Bologna, Italy, 57, 113.

[16] Luisi, P.L.: 2006, The Emergence of Life. From Chemical Origin to Synthetic Biology, Cambridge Univeristy Press.

[17] Mikolajewska, J.: 2017, talk at the Palermo Workshop on "The Golden Age of Cataclysmic Variables and Related Objects - IV".

[18] Piran, T.: 1999, Phys. Rep. 314, Issue 6, 575-667.

[19] Rolle, F.: 1863, Ch.Darwin's Lehre von der Entstehung der Arten, in J.C. Hermann, Ihrer Anwendung auf die Schöpfunggeschichte.

[20] de Saint Exupéry, Antoine: 1943, Le Petit Prince, Gallimard, France. English version The Little Prince, Reynal \& Hitchcock, U.S.A.

[21] Salahuddin Armstrong, P.: 2014, April 13, Speech originally delivered at the New Humanity Movement event.

[22] Shara, M.M., Ilkiewicz, K, Mikolajewska, J., Pagnotta, A., Michael F. Bode, M.F., et al.: 2017, arXiv:1704.00086v1.

[23] Soka Gakkai Internationsl: 1999, The Writings of Nichiren Daishonin, Vol. 1, p. 196. 